\title{
Our Oceans-Our Future: New Evidence-based Sea Level Records from the Fiji Islands for the Last 500 years Indicating Rotational Eustasy and Absence of a Present Rise in Sea Level Nils-Axel Mörner
}

Paleogeophysics \& Geodynamics, Stockholm, Sweden

\begin{abstract}
Previously, no study in the Fiji Islands had been devoted to the sea level changes of the last 500 years. No serious prediction can be made unless we have a good understanding of the sea level changes today and in the past centuries. Therefore, this study fills a gap, and provides real observational facts to assess the question of present sea level changes. There is a total absence of data supporting the notion of a present sea level rise; on the contrary all available facts indicate present sea level stability. On the centennial timescale, there was a $+70 \mathrm{~cm}$ high level in the 16 th and 17 th centuries, a $-50 \mathrm{~cm}$ low in the 18 th century and a stability (with some oscillations) in the 19th, 20th and early 21st centuries. This is almost identical to the sea level change documented in the Maldives, Bangladesh and Goa (India). This seems to indicate a mutual driving force. However, the recorded sea level changes are anti-correlated with the major changes in climate during the last 600 years. Therefore, glacial eustasy cannot be the driving force. The explanation seems to be rotational eustasy with speeding-up phases during Grand Solar Minima forcing ocean water masses to the equatorial region, and slowing-down phases during Grand Solar Maxima forcing ocean waster massed from the equator towards the poles.
\end{abstract}

Publication History:

\section{Background}

The Intergovernmental Panel on Climate Change [1] has claimed that sea level is rising and that an additional acceleration is soon to be expected as a function of global warming. This proposition only works if the present warming would be a function of increased $\mathrm{CO} 2$ content in the atmosphere (a hypothesis termed AGW from Anthropogenic Global Warming). On a longer-term basis, it seems quite clear, however, that the dominant factor of global changes in temperature is changes in solar variability [2-3]. Regardless of what actually is driving climate change and sea level changes, the proposition of a rapidly rising sea level grew to a mantra in media and politics. This initiated a flood of papers rather based on models and statistics, however, than on actual field observations.

The Fiji government will be the chair-nation at the next international climate conference; COP23 in Bonn in November 2017 [4].

This paper represents a detailed analysis of available field observation on sea level changes in the Fiji Islands over the last 500 years

\section{Methods}

The Fiji Islands consists of over 300 islands. From a survey of available literature(e.g. [5-8]), the Yasawa Islands were chosen for our field studies [9]. On Google Earth it is now possible to examine coastal segments in quite a great detail, and to select promising sites for field studies at ground. Ten sites on the Yasawa Islands were selected [9], because it seemed possible to investigate also the sea level changes during the last 500-600 years (a period not covered by previous studies).

At site, we explored the morphological structures in view of past and sub-recent sea level changes. The high tide level (HTL) was generally marked by distinct features like shore notches, under-cut notches, sea caves, rock-cut platforms and sandy shore morphology. This level was chosen as our zero level for measurements. The mean tide level (MTL) and low tide level (LTL) were explored and measured as to elevation. Leveling was undertaken with a high precision Kern instrument with a reading accuracy better than $1 \mathrm{~cm}$.

Samples were collected, 17 of which were radiocarbon dated (at the Uppsala AMS dating laboratory).

At several sites, we observed coral grown into "microatolls" because of stable sea level conditions. The controlling water depth was sharply measured to $40 \mathrm{~cm}$ below LTL.

\section{Results}

On the main island of Viti Levu, there are two tide gauge stations. We analysed their location, susceptibility to compaction of the marine soft sediment upon which the harbour constructions are resting, and the location and implication of nearby GPS readings [10]. Both sites are very unfortunately placed on heavy wharf constructions resting on soft marine sediments. The load is likely to induce site-specific compaction. In addition, there may be a weak regional crustal subsidence factor.

The Suva station has often been used as some sort of Fiji standard of a long-term trend from 1972 to the present [11]. This is a serious mistake, however, because the record is cut in 3 incompatible segments from 3 different locations of the tide-gauges. This is illustrated in Figure 1 [10] revealing that the record, in fact, comes from three different tide gauge stations. The present location is from 1989.

"Corresponding Author: Prof. Nils-Axel Mörner, Paleogeophysics \& Geodynamics, Stockholm, Sweden; E-mail: morner@pog.nu

Citation: Mörner NA (2017) Our Oceans-Our Future: New Evidence-based Sea Level Records from the Fiji Islands for the Last 500 years Indicating Rotational Eustasy and Absence of a Present Rise in Sea Level. Int J Earth Environ Sci 2: 137. doi: https://doi.org/10.15344/2456-351X/2017/137

Copyright: ( 2017 Mörner. This is an open-access article distributed under the terms of the Creative Commons Attribution License, which permits unrestricted use, distribution, and reproduction in any medium, provided the original author and source are credited. 
Citation: Mörner NA (2017) Our Oceans-Our Future: New Evidence-based Sea Level Records from the Fiji Islands for the Last 500 years Indicating Rotational Eustasy and Absence of a Present Rise in Sea Level. Int J Earth Environ Sci 2: 137. doi: https://doi.org/10.15344/2456-351X/2017/137

Page 2 of 5

The record does not provide any mean trend, but a dynamic variability between 16 years of stability, 10 years of sea level rise and 4 years of sea level fall. Hence, there is a lack of evidence of a present rise in sea level.

We also analysed some sites of coastal erosion in Yasawa Islands [12]. In no case the erosion was initiated by sea level changes but by human interference with the coastal sedimentary conditions.

Our main sea level investigation was on the Yasawa Islands with the focus on sea level change during the last 500 years. A comprehensive presentation is given elsewhere [13], with a shorter summary in [14].In this paper we highlight the main findings, which can be summarized in 3 steps from about 1450 up to today (2017) as illustrated in Figure 2 .

1. $\mathrm{a}+70 \mathrm{~cm}$ level in the $16 \mathrm{th}$ and 17 th centuries

\section{2. a $-50 \mathrm{~cm}$ low level in the 18 th century}

3. a level at about $\pm 0.0 \mathrm{~cm}$ in the 19th, 20th and $21 \mathrm{st}$ centuries probably with $+30 \mathrm{~cm}$ peak in early 19th century, and a $10-20 \mathrm{~cm}$ lowering in the late 20th century but with strictly stable condition in the last decades

The $+70 \mathrm{~cm}$ is very well established by an elevated beach and a bedrock notch both levelled with an accuracy of $1 \mathrm{~cm}$. In addition there are several old shore terraces at an elevation of about 0.5 to $1.0 \mathrm{~m}$ above present sea level. Two C14-dates provide a calibrated age (with a marine reservoir effect of $450 \pm 30$ years) of $\mathrm{AD} 1601 \pm 143$ and 1576 \pm 71 , respectively.

This high level was followed by a low level with the HTL displaced to a position of about $20-30 \mathrm{~m}$ above present LTL. This corresponds to a mean sea level of about $-50 \mathrm{~cm}$. This low level seems to have occurred in the 18th century. At present, we lack any strict C14-date, however.

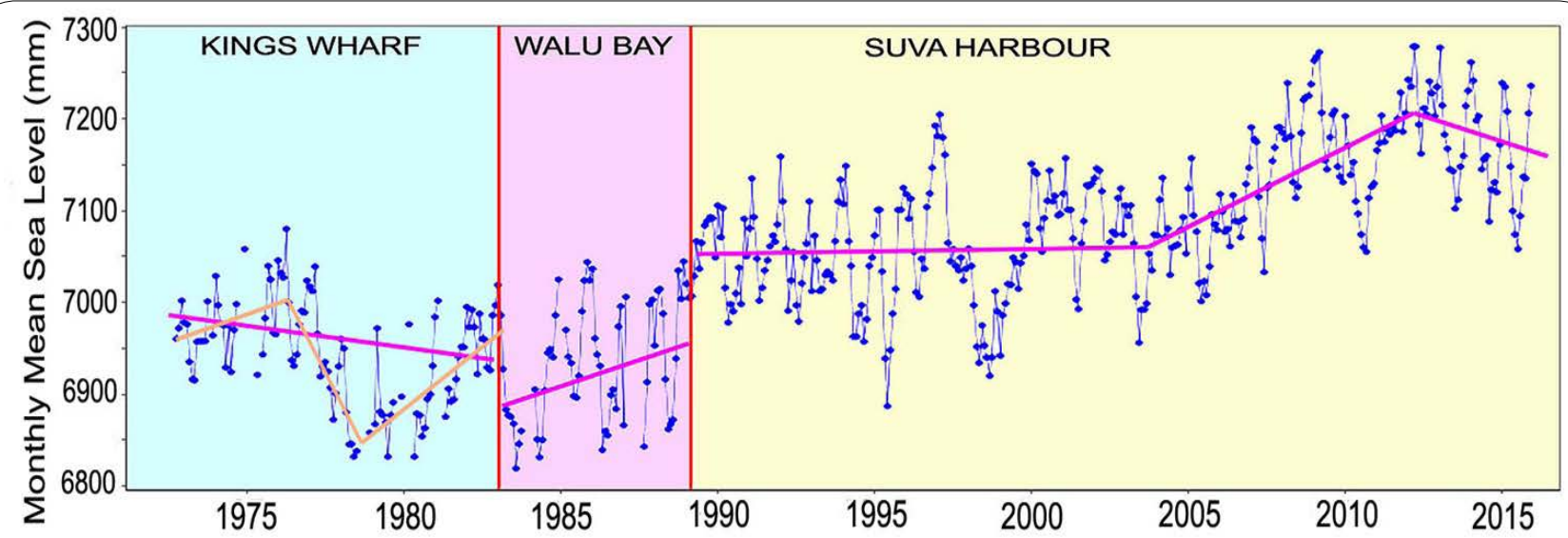

Figure 1: The Suva tide gauge records as recorded at three independent sites, which must be analysed individually and must not be combined in one single trend analyses (as done in [11]). Modified from [10].

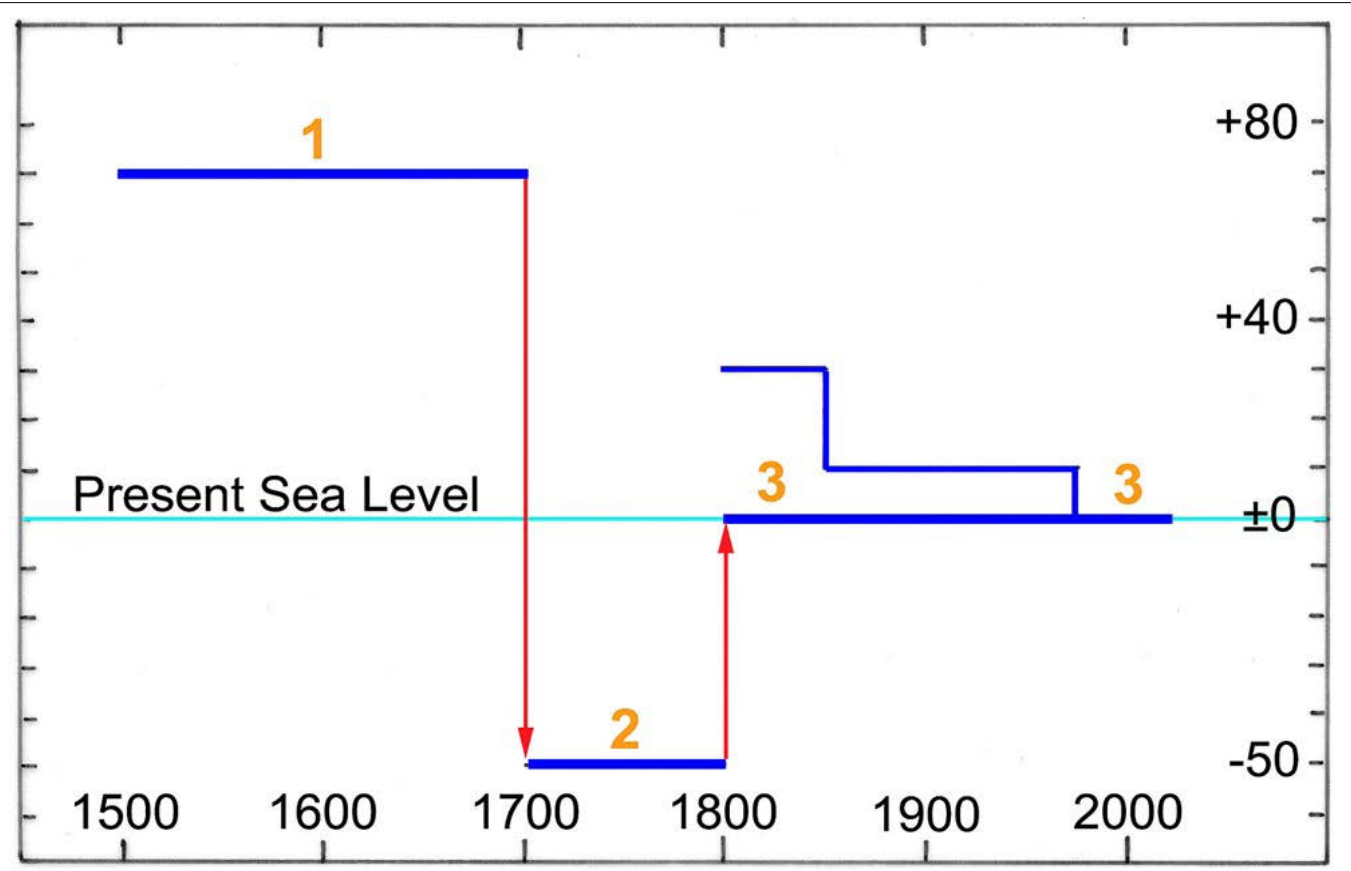

Figure 2: Sea level changes as documented in the Yasawa Islands, Fiji, composed of 3 main segments: a high level (1), a low level (3) and a more or less constant level (3), which might be subdivided (thin blue line) in an early high level, a main level just above the present level and a lowering to the present level generating microatoll growth in the last 60 years (based on data from [13]). 
Citation: Mörner NA (2017) Our Oceans-Our Future: New Evidence-based Sea Level Records from the Fiji Islands for the Last 500 years Indicating Rotational Eustasy and Absence of a Present Rise in Sea Level. Int J Earth Environ Sci 2: 137. doi: https://doi.org/10.15344/2456-351X/2017/137

Page 3 of 5

Then followed a period of continual formation of extensive spits and spurs. Three of those were levelled in detail [13]. A shore spur at Naisisili Village on Nabukeru Island is $155 \mathrm{~m}$ long. The spur crest is about $30 \mathrm{~cm}$ higher for the first $50 \mathrm{~m}$ and then remains quite flat at an elevation of about $50 \mathrm{~cm}$ above HTL. Shells taken $30 \mathrm{~cm}$ below the surface at the innermost part of the spur was dated at AD cal. $1866 \pm 82$, suggesting that the spur was built our at a mean rate of about $1.0 \mathrm{~m}$ per year, which seems reasonable. A shore spur at Gunu Village on the Malevu Island has a double spur system. The elevation remains more or less constant at 40-50 cm above HTL over its length of about $150 \mathrm{~m}$. Shells at a depth of 40-50 cm below the surface at a point $47 \mathrm{~m}$ from the onset of spur formation were dated at $\mathrm{AD}$ cal. $1910 \pm 40$. Both sites strongly support stable sea level conditions over the last 150 to 200 years. In the first 50 years or so, sea level might have been about $30 \mathrm{~cm}$ higher than today, however.

In the last 50-60 years, there might have been a $10-20 \mathrm{~cm}$ sea level lowering, judging from the difference between dead Patella shells and living Patella shells on shore blocks at Denarau on Viti Levu [13], and the forced conditions for corals on Yasawa Islands to grow into microatolls dated as younger than AD 1955. The 1998 ENSO event may also have caused extensive coral breaching. If this would have been the case, we see very strictly stable sea level conditions in the last 15-20 years, because so many corals at multiple sites are forced to grow laterally into microatolls.

Figure 2 gives the combined documentation of sea level change during the last 500 years in the Fiji Islands.

\section{Discussion}

We revised the records from the two tide gauges on the main island of Viti Levu [10], and showed that location must be seriously analysed with respect to site-specific compaction of loose marine deposits beneath the heavy harbour construction upon which the tide gauges are attached. At Suva, there is another serious problem in the fact that the location of the tide gauge has been moved. This gives 3 independent segments (Figure 1). It is a serious mistake to combine all three records into one, and give a mean rising trend from 1972 to the present [11]. Even the record from the last site in Suva harbour, now covering 28 years, gives a very unclear picture (Figure 1).

No previous investigation has covered the sea level changes of the last 500 years. In this respect our Yasawa Island investigation [13] is unique.

The Yasawa Island investigation provided a clear picture of the sea level changes during the last 500 years (Figure 2): $\mathrm{a}+70 \mathrm{~cm}$ higher sea level, a $-50 \mathrm{~cm}$ lower sea level and a stable sea level (with some possible ups and downs) for the last 150-200 years. Most important; there is a clear absence of a present sea level rise (completely contrary to [1], but in full agreement with [15]).

The long-term changes during the last 500 years - i.e. a high, a low and a present level - is recorded in the Maldives [16], in Bangladesh [17-18] and in Goa, India, [15,18], as illustrated in Figure 3. A present long-term stability is also recorded in Qatar [19].

The general agreement between the observed sea level changes in Fiji during the last 500 years, and those recorded in the three Indian Ocean sites: the Maldives, Goa and Bangladesh is striking, which is a very strong (even conclusive) argument that the recorded sea level change are of regional eustatic origin [20].

All four records show a high in the 17 th century (which was a period of Little Ice Age conditions), a low in the 18th century (which was a period nearly as warm as today) and a high in the early 19th

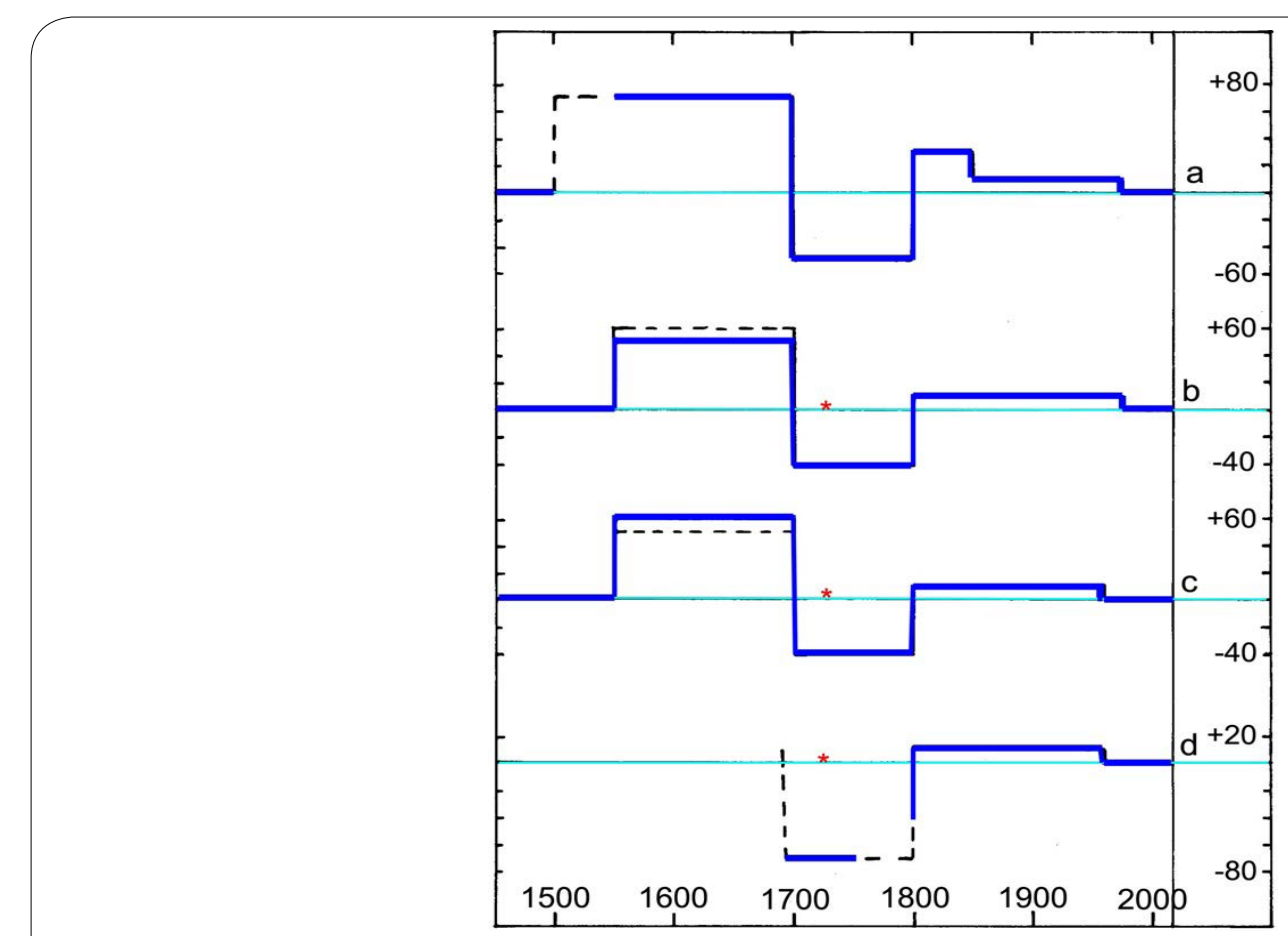

Figure 3: Observed sea level changes during the last 500 years in (a) the Fiji Islands [13], (b) the Maldives [16, 18], (c) Goa [15, 18], and (d) Bangladesh [17], [18]. The sharp corners of the blue curves are a function of the identification of the high and low levels neglecting more real transitional curvatures. Red stars mark the 1733 tsunami event $[15,18,27]$. 
Citation: Mörner NA (2017) Our Oceans-Our Future: New Evidence-based Sea Level Records from the Fiji Islands for the Last 500 years Indicating Rotational Eustasy and Absence of a Present Rise in Sea Level. Int J Earth Environ Sci 2: 137. doi: https://doi.org/10.15344/2456-351X/2017/137

Page 4 of 5

century (which was the last period of Little Ice Age conditions) This means that the Figure 3 sea level changes are almost directly opposite to the general changes in global climate. Consequently, the eustatic changes recorded cannot refer to glacial eustasy, but must be understood in terms of rotational eustasy.

This calls for some explanation. The idea that oceanic water masses may be dislocated horizontally by rotational-dynamical forces was launched in 1984 [21] and more extensively presented in 1988 [22]. Later, is was proposed that changes in the Solar Wind strongly affects the Earth's rate of rotation [23] (with a deeper analysis in [24]) leading to a beat in the Gulf Stream with alternations between a dominant northeastward flow during rotational slowing-down periods of Grand Solar Maxima, and dominant east-south eastward flow during rotational seeding-up periods of Grand Solar Minima [25].

The sea level changes in the Indian Ocean, were therefore proposed $[26,15]$ to be driven by rotational eustasy; i.e. the interchanges of water masses between high-latitudes and the equatorial region as a function of the speeding-up during Grand Solar Minima with Little Ice Age conditions and slowing-down during Grand Solar Maxima with generally warm climatic conditions.

In the post-Little Ice Ages period from 1850 up to 1930-1940 there was a global glacial eustatic rise in the order of $11 \mathrm{~cm} \mathrm{[28].} \mathrm{For} \mathrm{the}$ rest of the last 500 years, rotational eustasy seems to have been the dominant factor as documented in Figure 3 and illustrated in Figure 4 .

\section{Conclusion}

Previously, the changes in sea level during the last 500 years were not covered by adequate research in the Fiji Islands. The present paper provides a detailed analyses documenting a $+70 \mathrm{~cm}$ high level in the 16th and 17 th centuries, a $-50 \mathrm{~cm}$ low in the 18 th century and a period of virtually stability in the 19th to early 21 st centuries, the last period of which may be subdivided into an early 19th century $+30 \mathrm{~cm}$ high, a long period of stability and a $10-20 \mathrm{~cm}$ fall in sea level in the last 60 years forcing corals to grew into microatolls under strictly stable sea level conditions. This means there are no traces of a present rise in sea level; on the contrary: full stability.
The long-term trend is almost identical to the trends documented in the Indian Ocean in the Maldives, Goa and Bangladesh. This implies a eustatic origin of the changes recorded; not of glacial eustatic origin, however, but of rotational eustatic origin.

The rotational eustatic changes in sea level are driven by the alternations of speeding-up during Grand Solar Minima (the Maunder and Dalton Solar Minima) forcing water towards the equator, and slowing-down during Grand Solar Maxima (in the 18th century, around 1930-1940 and at about 1970-2000).

\section{Competing Interests}

The author assures that there is no competing interest, either economically or scientifically.

\section{Acknowledgements}

I acknowledge the perfect assistance in the field by Pamela MatlackKlein, co-author of all the basic Fiji papers of the project $[9,10]$, $[12,13]$. The project was made possible thanks to kind support of the $\mathrm{CO} 2$ Coalition. This paper represents the content of a paper presented at the 4th World Conference on Climate Change in Rome, 2017 [14].

\section{References}

1. The Intergovernmental Panel on Climate Change (2013) Climate Change 2013: The Physics Science Basis, WHO and UNEP.

2. Mörner NA, Tattersall R, Solheim JE (2013) Pattern in solar variability. Their planetary origin and terrestrial impact. Pattern Recognition in Physics 1: 203-204.

3. Mörner NA (2015) Planetary Influence on the Sun and the Earth, and a Modern Book-Burning. New York: Nova Publishers, USA, $196 \mathrm{p}$.

4. COP, 2017

5. Nunn, PD (2000) Significance of emerged Holocene corals around Ovalau and Moturiki islands, Fiji, southwest Pacific. Marine Geology 163: 345-351.

6. Nunn PD, Ollier C, Hope G, Rodda P, Omura A, et al. (2002) Late Quaternary Sea-Level and Tectonic Changes in Northeast Fiji. Marine Geology 187: 299-311.

7. Nunn PD, Peltier WR(2001) Far-field test of the ICE-4G model of global isostatic response to deglaciation using empirical and theoretical Holocene sea-level reconstructions for the Fiji Islands, southwestern Pacific. Quaternary Research 55: 203-214.

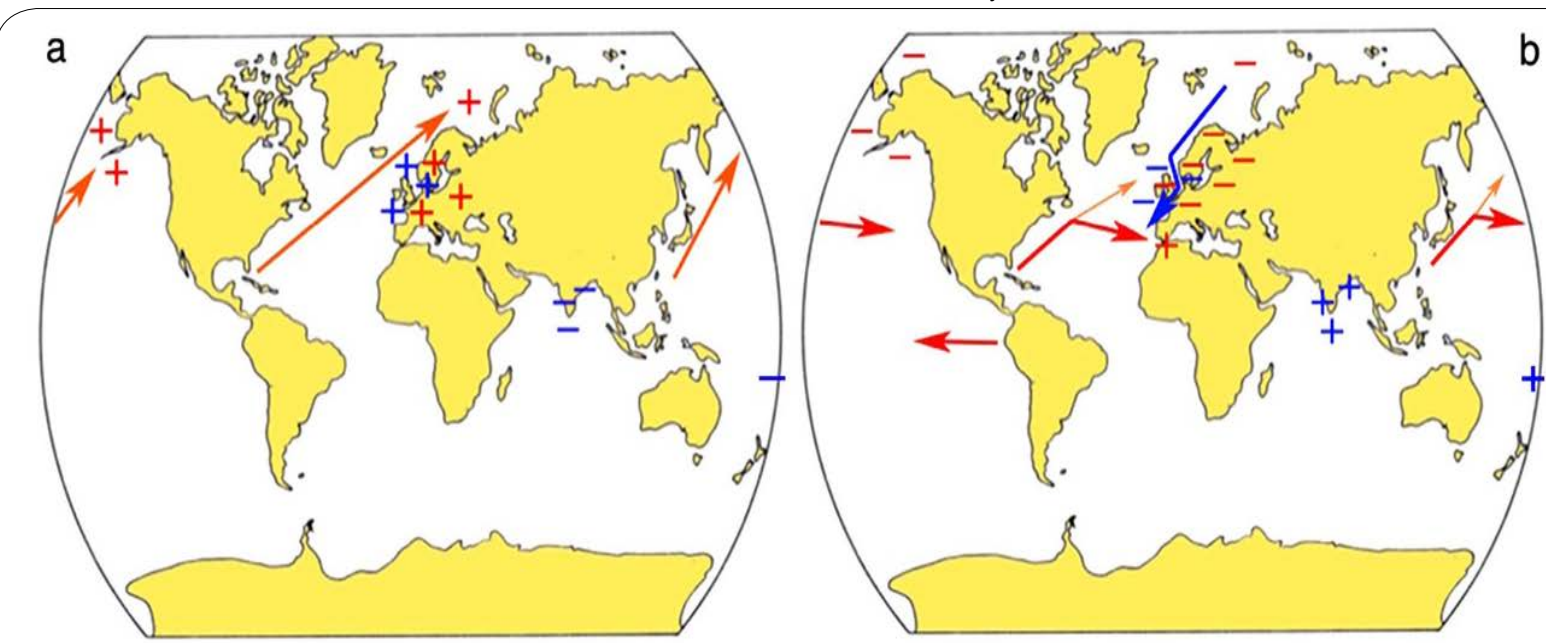

Figure 4: Ocean circulation (arrows), temperature changes (red), and sea- level changes (blue) in the equatorial Indian Ocean and Pacific, and in the NE Atlantic and Scandinavian regions during Grand Solar Minima (a) with rotational slowing-down and Grand Solar Maxima (b) with rotational speeding-up (modified from $[15,26]$ ). 
Citation: Mörner NA (2017) Our Oceans-Our Future: New Evidence-based Sea Level Records from the Fiji Islands for the Last 500 years Indicating Rotational Eustasy and Absence of a Present Rise in Sea Level. Int J Earth Environ Sci 2: 137. doi: https://doi.org/10.15344/2456-351X/2017/137

Page 5 of 5

8. Nunn PD, Omura A (2004) Penultimate Interglacial emerged reef around Kadavu Island, southwest Pacific: implications for late Quaternary island-arc tectonics and sea level history. New Zealand Journal Geology Geophysics 42: 219-227.

9. Mörner NA, Matlack-Klein P (2017) The Fiji sea level project. ResearchGate.

10. Mörner NA, Matlack-Klein P (2017) The Fiji tide-gauge stations. International Journal of Geosciences 8: 536-544.

11. PSMSL.

12. Mörner N-A, Matlack-Klein P (2017) Coastal erosion in Yasawa Islands, Fiji. Natural Science 9: 136-142.

13. Mörner NA, Matlack-Klein P (2017) New records of sea level changes in the Fiji Islands. Journal of Coastal Research, submitted.

14. Mörner N-A, Matlack-Klein P, Soon W (2017) Our Oceans - Our Future: New evidence-based sea level records from the Fiji Islands indicating no rise in ocean level. 4th World Conference on Climate Change, Rome, Italy

15. Mörner NA (1917) Coastal morphology and sea-level changes in Goa India, during the last 500 years. Journal of Coastal Research 33: 421-434.

16. Mörner NA (2007) Sea level changes and tsunamis, environmental stress and migration overseas. The case of the Maldives and Sri Lanka. Internationales Asienforum 38: 353-374.

17. Mörner NA (2010) Sea level changes in Bangladesh New observational facts. Energy \& Environment 21: 235-249.

18. Mörner NA (2016) Sea level changes as observed in nature. In: Easterbrook DJ (Ed) Evidence-Based Climate Science, 2nd Revised Edition, Elsevier, Amsterdam, Netherlands, pp. 219-231.

19. Mörner NA (2015) The flooding of Ur in Mesopotamia in new perspectives Archaeological Discovery 3: 26-31.

20. Mörner NA (2013) Sea level changes: past records and future expectations. Earth \& Environment 24: 509-536.

21. Mörner NA (1984) Planetary, solar, atmospheric, hydrospheric and endogene processes as origin of climatic changes on the Earth. In: Mörner $\mathrm{N}-\mathrm{A}$, Karlén W (Eds), Climatic Changes on a Yearly to Millennial Basis, Reidel Publ. Co, Dordrecht//Boston/ Lancaster), pp. 483-507.

22. Mörner NA (1988) Terrestrial variations within given energy, mass and momentum budgets; Paleoclimate, sea level, paleomagnetism, differential rotation and geodynamics. In: Stephenson FR, Wolfendale AW(Eds.) Secular Solar and Geomagnetic Variations in the last 10,000 years, Kluwer Acad. Press, pp. 455-478.

23. Mörner NA (1996) Global change and interaction of Earth rotation, ocean circulation and paleoclimate. Anais da Academia Brasileira de Ciencias 68: 77-94

24. Mörner NA (2013) Planetary beat and solar-terrestrial responses. Pattern Recogn Phys 1: 107-116.

25. Mörner NA (2010) Solar minima, Earth's rotation and Little Ice Ages in the past and in the future. The North Atlantic-European case. Global and Planetary Change 72: 282-293.

26. Mörner NA (2015) Multiple planetary influences on the Earth. In: Mörner $\mathrm{N}-\mathrm{A}(\mathrm{Ed})$ Planetary Influence on the Sun and the Earth, and a Modern Book-Burning, Nova, New York, USA, pp.39-50.

27. Mörner NA, Laborel J, Dawson S (2008) Submarine "sandstorms"and tsunami events in the Indian Ocean. Journal of Coastal Research 24: 16081611.

28. Mörner NA (1992) Sea level changes and Earth's rate of rotation. Journal of Coastal Research 8: 966-971. 